CZU:821.135.1.09(478)

https://doi.org/10.52505/filomod.2021.15.09

\title{
MIGRANTUL DIN EST: EXERCIȚII DE SUPRAVIEȚUIRE
}

\author{
FeLicia CENUȘĂ \\ Institutul de Filologie Română „B. P.-Hasdeu” al MEC
}

\begin{abstract}
Rezumat. În studiul de față ne vom referi la experiența de emigrant a românilor din Est reflectată în romanul „Clownul din lemn de gutui” de Radu Jorgensen și în piesele de teatru „Avant de mourir" de Val Butnaru, „In container" de Constantin Cheianu și „Oameni ai nimănui” de Dumitru Crudu. Textele se bazează pe fapte reale și constituie o radiografiere a celor mai dramatice crize cu care se confruntă emigrantul azi convertite în ficțiune. Autorii nu urmăresc să-și impresioneze cititorii cu strategii discursive sau didascalii deosebite. Ei încearcă să-i atragă și să-i sensibilizeze prin fabulă și mesaj. Impresia de autenticitate în textele menționate este sporită de multitudinea detaliilor și de marcanta tensiune a mărturisirii.
\end{abstract}

Cuvinte-cheie: emigrant, roman, dramaturgie, tranziție, libertate.

Abstract. In the present study we will refer to the emigrant experience of the Romanians from the East reflected in the novel The Quince Wooden Clown by Radu Jorgensen and in the plays Avant de mourir by Val Butnaru, In a container by Constantin Cheianu and Nobody's People by Dumitru Crudu. The texts are based on real facts and are an , $x$-ray" of the most dramatic crises faced by the emigrant today converted into fiction. The authors do not seek to impress their readers with special discursive strategies or captions. They try to attract and sensitize their audience through fable and message. The impression of authenticity in the mentioned texts is enhanced by the multitude of details and the strong tension of the confession.

Keywords: emigrant, novel, dramaturgy, transition, freedom.

Până la Independența Republicii Moldova, migrația a fost un fenomen sporadic și primordial politic. Pe la mijlocul anilor '90, din cauza paraliziei economice și a deznădejdii, a unui management defectuos în majoritatea domeniilor economice și sociale, a degradării materiale și spirituale începută în comunism, emigrația basarabeană ia amploare, marcată fiind de un mobil economic. Chiar dacă acest proces pare să nu fie unul permanent, ci un episod din perioada de declin economic, din cauza sărăciei și disperării, oamenii pleacă riscând totul: familie, prieteni, pasiuni, prezentul și viitorul. Negăsinduși rostul în propria țară, forța de aspirație a străinătătiii este vazută de către ei mai mult ca o alegere forțată a câmpului de luptă pentru supraviețuire, și mai puțin drept trambulină spre carieră.

În volumul de eseuri Don Quijote în Est, Octavian Paler mărturisește cu lux de amănunte despre problemele sinuoase ale esticilor veniți în Occident 
după căderea Cortinei de Fier, în speranța exercitării vechilor profesiuni. De regulă, aceștia sunt nevoiți să treacă prin ,ppurgatorii umilitoare, să-și vadă invalidate experiența, pregătirea, capacitatea, iluziile, să îndure privațiuni la care nu s-au așteptat, ori să facă munci pe care acasă le-ar fi socotit inferioare, până reușesc să-și asigure o situație mai stabilă, uneori, chiar mulțumitoare în plan material" (Paler, 2017, p. 17).

Apropiate, ca semnificație, mărturisirilor lui Octavian Paler sunt și destăinuirile scriitorului român emigrant Radu Jorgensen: „dacă prin eforturi disperate n-aș fi încercat să schimb subiectul, aruncându-1 într-o zonă a derizoriului, aș fi auzit până la capăt - am auzit acum, dar nu în flux continuu povestea unei inginere care spălase veceuri, a unui saxofonist care face pe translatorul, a câtorva mii de familii care... trăiesc pe social, adică pe ajutor de șomaj." (Jorgensen, 1998, p. 34) În plan sufletesc, acomodarea se dovedește un proces și mai dificil, rareori dus până la capăt. Aflându-se în țara adoptivă, azilantul descoperă că indiferența lumii libere poate fi la fel de crudă ca și cea din țara de origine.

În cartea sa Clownul din lemn de gutui, Radu Jorgensen, scriitor cu experiența emigrării, vorbește despre saga azilantului român în străinătate, mai exact, în Suedia. Cartea este „o ficțiune și trebuie tratată ca atare, chiar dacă se bazează pe fapte reale.”(Urian, 2000, p. 72). Un scriitor român, pentru a scăpa de libertatea controlată din țară, emigrează înfruntând o serie de probleme atât la plecare, cât și pe perioada șederii: „Am închis ochii întrerupând o clipă filmul neorealist care mi se desfășura înaintea lor. Dar ultima imagine, grotescă, ultimul cadru, persistă pe retină, colo sub pleoapa strânsă cu putere. Imaginea călătorilor trenului nostru „de luxe” sărind peste linii, sărind spre marginea triajului undeva ca să bea apă de la o cișmea, să se adape, alergând cu pașapoartele în mână să fie văzuți de forța magică și să fie mai apoi reprimiți în rândul călătorilor trenului ,de luxe”. După ce hidratarea lor, astâmpărarea setei lor animalice s-ar fi produs. Cu pașaportul într-o mână și cu pantofii cui într-alta sărind peste linii, cu fardul curs peste obraji, pe sub ochi, pe cutele gâtului, doamnele „de luxe" întorcându-se victorioase la trenul „de luxe” cu sticle „de juma” în mâini. Creierul magic le transferase acest ultim impuls, o avertizare-avertisment, ultimul bici pișcase crupele lor tresăltânde peste liniile ferate în triajul ultimei staţii din teritoriu." (Jorgensen, 1998, p. 15).

Autorul îi compară pe dezlănțuiții din Est cu niște animale proaspăt scăpate din cușcă: „Dresorul dăduse o ultimă reprezentație al cărei unic spectator el însuși fusese. Pentru a fi sigur de totala supunere a dresatelor și dresaților, a fiarelor cu ghearele retezate și manichiura făcută. Pentru a fi sigur că atunci când va ridica grilajul metalic eliberându-se din cușca-eveniment pentru care acele fiare mai întâi mușcaseră, zgâriaseră, însângeraseră și se însângeraseră, mai apoi răcniseră, urlaseră, iar în final, deși își pierduseră orice putere, continuau să grohăie, să geamă, să mugească tânjind - ele vor adulmeca libertatea cu nările dilatate o vreme, apoi îmbătate de aerul prea tare al libertății și neputincioase în a găsi logica junglei de afară, se vor întoarce 
din proprie voință în încă și mai complicata junglă dinăuntru." (Jorgensen, 1998, p. 14-15)

Mai mult, repulsia față de viața cotidiană, urâtul ce-l copleșea pe om în fața existenței lipsite de valoare se transformau subit într-o „psihoză a speranței”, susține Herta Muler în volumul de eseuri Regele se-nclină și ucide. Speranța în viață „o puteai dobândi doar înfruntând primejdia, dar totuși posibilă (speranța - n.n.) pe meleaguri străine. Instinctul fugii însoțea toate celelalte lucruri.” (Muller, 2005, p. 189) Omul nu vedea în această țară decât un loc vremelnic al vieții lui. Unicul sprijin dându-i credința că mai devreme sau mai târziu i se va oferi prilejul să fugă.

Și dramaturgul basarabean Val Butnaru, în piesa Avant de mourir, prezintă drama tulburătoare a artistului azilant dezrădăcinat și momentele pline de neliniște prin care trec cei nevoiţi să emigreze.

Personajele piesei sunt Ovidiu și Magdalena. Ovidiu părăsise satul natal, Mugurele, de ,paisprezece ani”, pe când „se apropia de 50”, luând calea străinătății pentru a câş̧iga un ban pentru familie. În încercarea de a supraviețui, ajunge la capătul puterilor, reușind de fiecare dată să supravieţuiască. El este ,prototipul sutelor de mii de basarabeni ce traversează de atâţia ani întunecatul tunel al interminabilei tranziţii din neunde spre nicăieri." (Zaharia, 2015). Amintind cumva de Ivan Ilici al lui Tolstoi, Ovidiu se află la ora bilanţurilor vieţii trăite ca un continuu rateu, motiv pentru care decide să-şi curme viaţa, dar şi aici clachează. Magdalena e la începutul carierei sale de artistă, plină de speranţe, dar marcată de disperarea condiţiei de emigrant. Entuziasmul său idealist trece prin probe dure, iar încercarea de a supraviețui în țara de adopție este presărată cu o serie de deziluzii însoţite de întrebarea „La ce bun să supravieţuieşti aici, printre străini?".

Acţiunea piesei se desfăşoară la Paris, orașul care adăpostește milioane de emigranți din toate colțurile lumii. Ovidiu, ajuns aici, după alte munci făcute în Europa, se declară instructor de dans și își deschide la subsolul unei clădiri un salon de dans, căruia îi face publicitate în ziarele pariziene. Unul dintre candidații dornici de a lua lecții de la el este Magdalena, o actriță venită din Basarabia în „oraşul visurilor deşarte şi al îndrăgostiţilor leşinaţi”, iar tangoul lui Pantazi, alias Georges Boulanger, pe care urmează să-l interpreteze/danseze, ilustrează drama acestor oameni fără de ţară. Textul piesei este populat de cele două personaje care se completează reciproc în acest „tangou de adio”, dansat înainte de moarte, de unde și titlul piesei.

Fiica lui Ovidiu, Liliana, lăsată acum paisprezece ani acasă în Mugurele cu mamă-sa, moare în neștire la Paris:

„Magda: Liliana a murit.

Ovidiu: Ce tot spui? Cum a murit? Când?

Magda: Acum doi ani. Aici, la Paris.

Ovidiu: $\mathrm{Nu}$ poate fi... N-am știut nimic!

Magda: Nimeni nu știe.

Ovidiu: Dar ce căuta ea la Paris? 
Magda (erupe): Ceea ce caută toate fetele noastre în parisurile împuțite. [...] De când ai plecat, $n$-ai mai dat nicio veste. Îmi vorbea întruna de dumneata. Și într-o bună zi, am plecat împreună - să te căutăm. Acum doi ani, a fost înjunghiată într-un cartier la periferia Parisului. N-avea acte, n-avea identitate.

Ovidiu: Dar care-i vina mea?

Magda: Vina? Care-i vina ta, mă întrebi? Ticăloșilor, ați plecat cu toții! Mugurelele-s pustii, ca după război! Ați plecat fără să priviți înapoi! Și noi? Și noi cui ne-ați lăsat? La noi cine s-a gândit? [...] Cum te vei descurca? Unde vei găsi bani? Ai să-ți vinzi și pe cel de-al doilea rinichi? Ce a mai rămas de vânzare? Ficatul? Inima? Ochii?

Ovidiu: Am să-mi găsesc de lucru!

Magda: Ce poți să faci? Să îngrijești de un bătrân? Să dai lecții de dans?

Ovidiu: Sunt muzicant! Și pictor! Am făcut Arhitectura! Pot scrie! Am să mă angajez ca jurnalist!

Magda: Jurnalist? Nici măcar nu cunoști franceza!"

Magda, spre final, tunsă zero, își scoate peruca și îl cheamă pe Ovidiu să meargă acasă:

„Ovidiu: De ce nu putem rămâne aici?

Magda: Fiindcă orice om trebuie să moară acasă. Acest adevăr ni se potrivește de minune. N-ai înțeles că ambii suntem la fel? Ovidiu, am și eu o ultimă dorință: vreau să dansezi cu mine."

Dansul, care constituie intriga şi elementul coagulant al piesei, pare a fi un dans al morții, un Totentanz planând permanent asupra personajelor.

Textul nu e doar despre migrație, ci și o parabolă a dragostei și morții, a rostului artei în epoca dezumanizării, a angoasei traumatizante în vremuri vitrege. A trăi departe de limba ta şi de mulţi dintre ai tăi e sursa multor vise tulburi pentru orice emigrant, indiferent de locul de unde a plecat şi cel unde a ajuns, de la Ovidiu încoace. Nu întâmplător și personajul piesei se numește Ovidiu, destinul căruia pare a fie complementar poveștii de viață a personajului.

Tema plecării în străinătate pentru o viață mai bună o întâlnim și în piesa de teatru In container a basarabeanului Constantin Cheianu, în care trei moldoveni - Viorel, Sergiu și Igor - aflați la Bruxeles, un oraș de tranzit de unde urmează să-și continue drumul, îşi povestesc despre tentativele de a fugi din țară şi de a ajunge în Occident, considerat un Eldorado pentru mulți azilanți, dar care, de fapt, e spațiul care îi respinge, piesa fiind o mărturie cutremurătoare despre migrația ilegală a basarabenilor în Occident.

Personajele sunt niște "Odisei sau Telemahi ai epocii postcomuniste” (Crețu, 2014) care parcurg un traseu inițiatic, unul al umilinței, presărat cu interogatorii și cedări morale în încercarea de a traversa granițele. Întru realizarea visului de a ajunge în Europa, ei sunt gată să fie prinşi de roata de rezervă a vreunui tir, legați sub vreo remorcă, sau închiși ermetic în vreun container respirând printr-un furtun improvizat. În cazuri mai rare, își pot cumpăra la prețuri exagerate pașapoarte false, doar ca să treacă hotarul. Dacă părinţii lor trăiau permanent spaima de autoritățile sovietice, care pe mulți i-au deportat prin kazahstane sau siberii, cei trei trăiesc cu frica de autorităţile 
europene, care îi pot prinde, amenda și deporta acasă. Deşi par nişte hoți (aşa se prezintă unul dintre personaje) care își fură banii și paşapoartele unul altuia, iar legislaţia europeană îi plasează direct în rândul infractorilor, aceştia sunt de fapt niște „oameni ai nimănui”, respinși atât de țara de origini, cât și de cea de adopție.

În ultima parte, piesa lui Constantin Cheianu se mută din registrul documentarului, în cel al parabolei. Autorul adoptă această formulă cu sensuri existențiale profunde desprinse din realitate. Vedem un personaj dedublat care susține un dialog cu sine însuși, autorul insistând pe radiografierea trăirilor lăuntrice ale acestuia, prin introspecție și analiză psihologică. Din acest moment observăm și mutaţiile care se produc în tectonica sinelui în urma impactului produs de experiența nefastă.

Igor, unul din cele trei personaje, deposedat de bani de unul dintre camarazii săi, urmează să treacă granița într-un container închis ermetic, având posibilitatea să respire doar printr-un furtun improvizat. Tabloul amintește de biblicul Iona închis în burta imensă a unei balene. Personajul încearcă să se încurajeze rechemându-și trecutul, viața sa dinaintea intrării în containerul-balenă, monologând. Monologul personajului pare a fi și al scriitorului care înțelege însingurarea individului în societate, aflat mereu într-o dilemă: libertate și necesitate, între sens și nonsens. Monologul mai joacă și un rol de eliberare, un mijloc de a-și tempera frica. Am putea vorbi, totuși, de un monolog dialogat, întrucât personajul pare a vorbi cu mama sa, și ea o emigrantă în Italia:

„MAMA: Știi ce mi-am amintit eu? Cum te-am născut. Și cum îmi strigau medicii să am grijă să nu te înăbuș. Că te-am născut așa de greu.

IGOR: Eu, mama, mi-am amintit de bunica. Ea îmi povestea cum au fost ridicați de ruși și duși în vagoane pentru vite în Kazahstan. Zicea că vagonul avea doar o singură ferestruică țesută cu sârmă ghimpată și oamenii se înghesuiau la acea ferestruică să tragă câte o gură de aer curat. Înăuntru era mizerie, că ei acolo își făceau toate nevoile, nu le-au dat voie să iasă din vagon cinci zile. Așa și eu, mă simt că nu îmi ajunge aer, îmi apropii nasul de furtun. [...] Moldova noastră este un container. Îl agață cine vrea și îl duce unde poftește. Vrea în Kazahstan - îl duce în Kazahstan. Vrea în Europa, îl duce în Europa.... Mamă, noi suntem niște oameni de container. Oricine ne poate urca și ne poate duce unde dorește. Nici nu trebuie să ne urce, urcăm singuri. [...] Noi nu ne putem amesteca cu viaţa lor, zice, noi trăim parcă în nişte containere aici. Noi purtăm containerele noastre peste tot, ca şi melcul casa."

Aflat în burta balenei-container, personajul se prăpădește, nereușind s-o roage pe mama, ca în Iona lui Marin Sorescu, să-1 mai nască o dată, să-i mai dea o șansă: întrucât prima nu i-a prea ieșit. Moartea echivaleaza cu șansa eliberării totale. Autorul vine să ne demonstreze că nu atât moartea biologică este tragică, cât condițiile reprobabile care au condus spre aceasta. Personajul devine cu adevărat liber numai prin propria-i moarte, sfidând istoria bolnavă a timpului sau, încât nici însuși Dumnezeu nu-1 mai poate salva, precum procedase în cazul lui Iona. 
Tot despre „fuga” basarabenilor în străinătate este și piesa Oameni ai nimănui a lui Dumitru Crudu. Asemeni lui Constantin Cheianu, Dumitru Crudu se bazează pe materiale documentare pre-existente, pe mărturii, interviuri, inclusiv pe rapoarte guvernamentale. Metoda de lucru a celor doi dramaturgi este de a plasa acțiunea în mijlocul realității brute, fapt care dau pieselor o alură de autenticitate. Este real nu numai cadrul acțiunii, ci și cel de idei, inspirat dintr-o istorie contemporană.

Piesa poate servi drept catalizator al schimbărilor din societate, al sensibilizării lectorului, chiar dacă rareori vine cu soluții. Cele trei personaje ale piesei, Alexandru, Silvia şi Maria, aduc în prim-plan aceleaşi probleme majore ale individului silit să fugă de condițiile inumane de existență din Republica Moldova, precum foamea, sărăcia, dezamăgirea, zădărnicia și lipsa încrederii în ziua de mâine. Piesa se deschide cu o mărturie a lui Alexandru aflat în fața autogării, de unde urmează să plece în Italia: „Nimeni nu mai vrea să stea în țara asta. Nimeni. Nimeni nu mai vrea să aștepte timpuri mai bune. Toți se duc. Pur și simplu fug. Toată lumea își face bagajele. Se depărtează bărbați, femei, tineri, bătrâni, medici, ingineri, agronomi, arhitecți, vânzători, șoferi. Pleacă prietenii mei din școală, amicii mei din facultate, colegii mei de serviciu, verii, surorile mele. Sunt atâtea localități în care au rămas doar bătrânii. În curând am putea ajunge o țară fără locuitori. Toți știu lucrul ăsta, dar toți se evaporă de aici, inclusiv eu”.

Plecarea peste hotare a lui Alexandru e determinată nu doar de dorința de câștig, ci mai ales de disperare: este grav bolnav, are de întreținut un copil rămas în Moldova, bătut în fiecare seară de mama-sa alcoolică. A hotărât să-şi sacrifice ultimele zile pentru a face un ban „mai ușor”, îngrijind de un bărbat cu probleme psihice și de integritate pe care nu vrea să-1 părăsească, chiar dacă îl pune la încercări riscante, fie amenințându-l cu un cuțit, fie aruncând în el cu ce are la îndemână: ,În Italia e atât de greu să-ţi faci rost de un job. $\mathrm{Nu}$ vreau să-mi pierd obiectul muncii mele. Dacă rămân fără acest serviciu, cine o să mă ia în altă parte? Cine o să-1 angajeze altundeva pe un individ venit din Moldova, despre care aici nimeni n-a auzit nimic, nici măcar unde e pe hartă?", răspunde Alexandru atunci când e îndemnat de vecini să nu mai continue să îngrijească de ,ț̆cănit”.

Alături de Alexandru, celelalte două personaje ale piesei reprezintă acelaşi statut al victimei unei lumi distopice.

În scrierile autorilor români, în special ale celor basarabeni, condiția de emigrant e una mai degrabă dramatică și maladivă decât una valorificată pozitiv, protagoniștii fiind nişte victime ale destinului. Ori, cum spune, pe drept cuvânt, cercetătoarea Sanda Cordoș, că „noii nomazi ai Europei de astăzi” sunt ,,prizonieri sau victime ale destinului, mai curând protagoniștii unui exod decât eroi ai Odiseei." (Cordoș, 2012, p. 158-159)

În cazul pieselor dramatice cu această tematică, dar și în proză sau jurnale, autorii nu urmăresc să-şi impresioneze cititorii cu strategii discursive sofisticate sau di dascălii deosebite. Textele respective încearcă să sensibilizeze publicul prin fabulă și mesaj. Mai mult, sunt puse în lumină tonurile minore 
ale existenței, textele devenind niște mărturisiri în scris ale unor întâmplări reale convertite în ficțiune. Autorul coboară spre cele mai ascunse încăperi ale sufletului personajelor, fără a culmina într-un melodramatic naiv. Majoritatea textelor ce abordează problematica emigrantului estic se citesc cu ușurință, chiar cu voluptate, dând posibilitatea identificării lectorului cu personajele. Impresia de autenticitate în textele menționate este sporită de multitudinea detaliilor și de marcanta tensiune a mărturisirii.

\section{Referințe bibliografice:}

1. BUTNARU, Val. Cum Ecleziastul discută cu proverbele. Chișinău, 2008.

2. CHEIANU, Constantin. În container. Chișinău, 2007.

3. CORDOȘ, Sanda. Lumi din cuvinte. Reprezentări și identități în literatura română postbelică. București, 2012.

4. CREȚU, Bogdan. Ce inseamnă să fii moldovean? [online] Disponibil: https:// www.ziaruldeiasi.ro/stiri/ce-inseamna-sa-fii-moldovean--74292.html

5. CRUDU, Dumitru. Oameni ai nimănui, Chișinău, 2007.

6. JORGENSEN, Radu. Clovnul din lemn de gutui. București, 1998

7. MULLER, Herta. Regele se-nclină și ucide. Traducere din germană și note de Alexandru Al.Șaghian. București, 2017.

8. PALẺR, Octavian. Don Quijote în Est. Iași, 2017

9. URIAN, Tudorel. Proza românească a anilor 90. Chișinău, 2000.

10. ZAHARIA, Viorica. Val Butnaru şi teatrul prezentului.[online] Disponibil: http://dir.upsc.md:8080/xmlui/bitstream/handle/123456789/908/ZAHARIA_VAL_ BUTNARU_SI_TEATRUL_PREZENTULUI.pdf? sequence $=1$ \&isAllowed $=\mathrm{y}$

Notă: Articolul a fost realizat în cadrul proiectului de cercetare 20.80009.1606.03 Contexte socioculturale autohtone şi interconexiuni europene în creaţia populară şi literatura cultă din Basarabia (sec. XIX până în prezent), Institutul de Filologie Română „B. P.-Hasdeu” al MEC. 